\title{
Analysis of recovery effect in supercapacitors for wearable devices
}

Conference or Workshop Item

Accepted Version

Arora, H., Sherratt, R. S., Janko, B. and Harwin, W. (2017) Analysis of recovery effect in supercapacitors for wearable devices. In: IEEE International Conference on Consumer Electronics, 8-10 Jan 2017, Las Vegas, USA. doi: https://doi.org/10.1109/ICCE.2017.7889322 Available at http://centaur.reading.ac.uk/67914/

It is advisable to refer to the publisher's version if you intend to cite from the work. See Guidance on citing.

Published version at: http://ieeexplore.ieee.org/document/7889322

To link to this article DOI: http://dx.doi.org/10.1109/ICCE.2017.7889322

All outputs in CentAUR are protected by Intellectual Property Rights law, including copyright law. Copyright and IPR is retained by the creators or other copyright holders. Terms and conditions for use of this material are defined in the End User Agreement. 


\section{www.reading.ac.uk/centaur}

\section{CentAUR}

Central Archive at the University of Reading

Reading's research outputs online 


\title{
Analysis of Recovery Effect in Supercapacitors for Wearable Devices
}

\author{
Harneet Arora, R. Simon Sherratt, Fellow, IEEE, Balazs Janko, William Harwin, Senior Member, IEEE \\ Department of Biomedical Engineering, University of Reading, UK \\ h.arora@pgr.reading.ac.uk, sherratt@ieee.org,b.janko@reading.ac.uk,w.s.harwin@reading.ac.uk
}

\begin{abstract}
Supercapacitors are likely to be adopted as power sources for wearable sensors; in particular where the sensor mechanism relies on energy harvesting. A specific advantage of supercapacitors over traditional batteries is their performance over large numbers of discharge cycles. Likewise, in the case of wearable devices, it is essential to efficiently manage the available power. Supercapacitors exhibit a small recovery effect, in part due to ion diffusion. Modelling this effect allows an increase in available energy to be realized following the sleep times during a discharge cycle thus increasing the time between charging for wearables. This paper presents the increase in useful lifetime that can be achieved via the recovery effect in a typical wearable device.
\end{abstract}

\section{INTRODUCTION}

Recent advances in wearable technology have made it possible to create and deploy devices that can assist in healthcare applications by tracking and monitoring the activities and physiological parameters of people. It is desirable in these applications to have a continuous operation and uninterrupted connectivity. This would require the devices to have a long lifetime without having the need for frequent recharge or replacement [1]. Batteries are currently the most commonly used source but are constrained by their energy density and limited charge cycles making it essential to have an alternative that can overcome these factors and provide longer life span to the wearable [2]. While software solutions can be used to extend device lifetime [3], they do not fundamentally increase the available charge from the battery.

Supercapacitors are electrochemical devices that have high energy and power densities and provide a very large number of charge/discharge cycles and can hence be considered as a lightweight alternative to batteries. Their low internal resistance and high capacitance allow them to be used either as a standalone power source or in conjunction with batteries to provide extended lifetime [4]. However, it is still necessary to optimize the energy usage of a supercapacitor to ensure efficient utility. This paper extends wearable device lifetime by exploiting the recovery effect in supercapacitors [5].

\section{RECOVERY EFFECT}

The recovery effect is an intuitive phenomenon which allows a battery or supercapacitor to recover energy that would otherwise be lost if allowance was not made to rest between discharge cycles. This sleep time allows the

This work was performed under the SPHERE IRC funded by the UK Engineering and Physical Sciences Research Council (EPSRC), Grant $\mathrm{EP} / \mathrm{K} 031910 / 1$. supercapacitor to resume the discharging with a higher voltage [5]. The presence of this effect can be attributed to the redistribution of ions inside the porous electrode and desorption of gases from the electrode interface [6]. Fig. 1 depicts the increase in voltage achieved during rest interval between active modes.
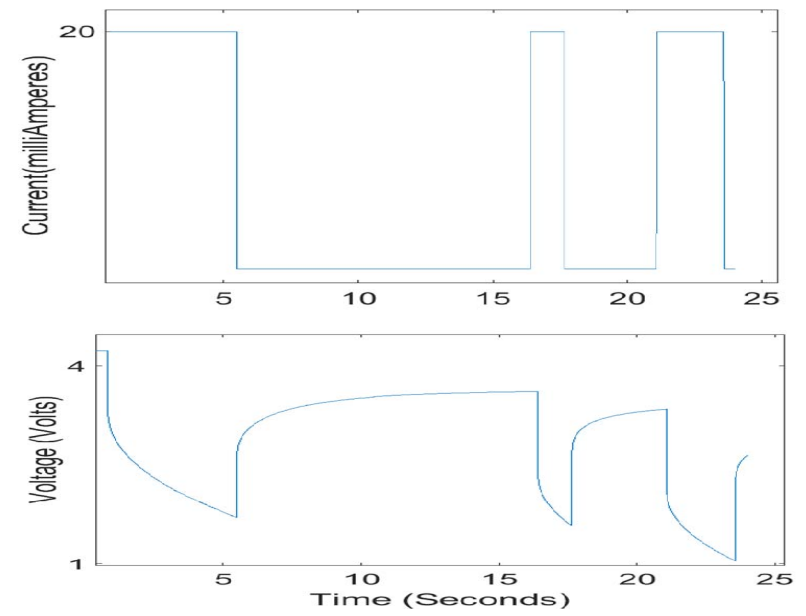

Fig. 1. Experimental data showing the rise in terminal voltage during sleep cycles which contribute towards the increase in total charge delivered.

The recovery effect can be utilized for a wearable sensor as it typically does not need to stay in an active state all the time. This is due to the fact that the parameters measured by wearables are less likely to change frequently. As such the device may enter in a low current, sleep mode between consecutive active periods so that recovery effect can take place allowing additional charge to be regained.

\section{EXPERIMENTS}

To validate the presence and amount of recovery possible, a current draining circuit was designed, sinking $20 \mathrm{~mA}$ for wearables typically heavy active time and a few $\mu \mathrm{A}$ in deep sleep. This broad range of values covers typical requirements of wearable devices. The large difference between these values should allow the process of redistribution of ions to take place in the supercapacitor during the low current discharge and hence enable it to have a maximum possible recovery. In the experiments a small button type supercapacitor was used which has a capacitance of $0.1 \mathrm{~F}$ and rated voltage of $5.5 \mathrm{~V}$. This supercapacitor was charged under constant current conditions to $80 \%$ of the rated voltage and 
was then held there for 30 minutes to allow the voltage to settle [7].

The duration of an active interval (A) was generated randomly between 1 and 5 seconds after each active-sleep cycle while sleep period (S) used is a multiple of the active duration. This proportion was varied to have a number of different discharge patterns. In this research, five discharge patterns were used: i) Continuous: no sleep time is given i.e. the supercapacitor is subjected to an uninterrupted discharge with maximum current $(20 \mathrm{~mA})$, ii) $\mathrm{S}=\mathrm{A}$ : Sleep time equal to active time, iii) $\mathrm{S}=2 \mathrm{~A}$ : Sleep time is twice the active time, iv) $\mathrm{S}=5 \mathrm{~A}$ : Sleep duration is 5 times the active duration and $\mathrm{v}$ ) $\mathrm{S}=10 \mathrm{~A}$ : sleep time is 10 times the active duration. Fig. 2 shows a section of one of the discharge patterns used. Three runs of each of these patterns were performed.

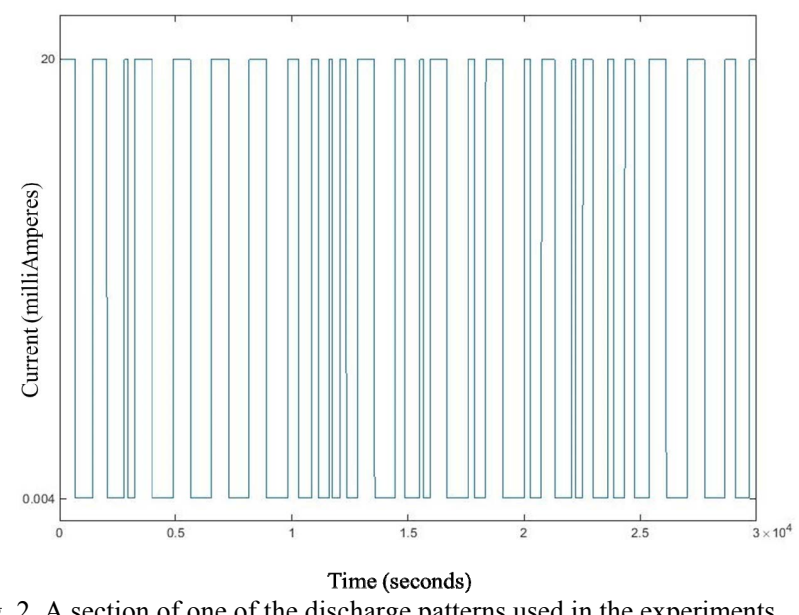

\section{RESUlTS AND Discussion}

To evaluate the effectiveness of sleep in the patterns above, two parameters were taken into consideration: i) increase in total active time achieved, and ii) overall charge consumption through coulomb counting. The results obtained are summarized in TABLE I and II. It can be observed that in the case of a continuous discharge the supercapacitor lasted for 19.11 seconds with the total charge utilization of $0.106 \mathrm{mAh}$. But with the insertion of sleep time, both active duration and charge delivered have increased markedly by $8.68 \%$ and $8.49 \%$ respectively in first discharge pattern with even higher gain achieved with increasing sleep durations in other patterns. The maximum gain noticed was of $21.69 \%$ when sleep was 10 times the active duration. Table II shows the values of percentage increase in active time and charge for each discharge pattern. The results from continuous discharge were considered as baseline values for these calculations. It can be inferred from these results that by putting the device to rest periodically significantly enhances supercapacitors available charge.

However, the gain achieved will not always rise with the increasing sleep durations as the self-discharge of the supercapacitor will become increasingly prominent and would need to be taken into further consideration.
TABLE I

Charge Utilized OVER DifFerent Discharge Patterns

\begin{tabular}{lllll}
\hline \hline $\begin{array}{l}\text { Discharge } \\
\text { Type }\end{array}$ & $\begin{array}{c}\text { Total Time } \\
(\mathrm{sec})\end{array}$ & $\begin{array}{c}\text { Active } \\
\text { Duration } \\
(\mathrm{sec})\end{array}$ & $\begin{array}{l}\text { Sleep } \\
\text { Duration } \\
(\mathrm{sec})\end{array}$ & $\begin{array}{l}\text { Charge } \\
\text { Utilized } \\
(\mathrm{mAh})\end{array}$ \\
\hline Continuous & 19.11 & 19.11 & 0 & 0.106 \\
$\mathrm{~S}=\mathrm{A}$ & 42.03 & 20.77 & 21.25 & 0.115 \\
$\mathrm{~S}=2 \mathrm{~A}$ & 74.14 & 21.68 & 52.46 & 0.120 \\
$\mathrm{~S}=5 \mathrm{~A}$ & 129.05 & 22.15 & 107.9 & 0.123 \\
$\mathrm{~S}=10 \mathrm{~A}$ & 259.20 & 23.28 & 235.92 & 0.129 \\
\hline \hline
\end{tabular}

TABLE II

INCREASE IN CHARGE UTILIZATION AND ACTIVE TIME W.R.T CONTINUOUS DISCHARGE

\begin{tabular}{lcc}
\hline \hline Discharge Type & $\begin{array}{c}\text { Increase in Charge Used } \\
(\%)\end{array}$ & $\begin{array}{c}\text { Increase in Active Time } \\
(\%)\end{array}$ \\
\hline $\mathrm{S}=\mathrm{A}$ & 8.49 & 8.68 \\
$\mathrm{~S}=2 \mathrm{~A}$ & 13.20 & 13.44 \\
$\mathrm{~S}=5 \mathrm{~A}$ & 16.03 & 15.90 \\
$\mathrm{~S}=10 \mathrm{~A}$ & 21.69 & 21.82 \\
\hline \hline
\end{tabular}

\section{CONCLUSIONS}

This paper has used the recovery effect to indicate the tremendous potential for energy recovery that can be achieved from supercapacitors used to power wearable devices. By the insertion of rest durations between discharge cycles that reflect active and sleep states, experiments have clearly shown that long sleep cycles increase the available energy that can be utilized. In this work, an extra $21.69 \%$ was achieved allowing the components using a supercapacitor to have a longer useful life between recharges. This work is beneficial for certain wearable devices that require a longer lifespan and can afford rest periods in between active discharges, which in turn allows for smaller batteries or smaller energy harvesting systems to be used. Also, as this property simply implements the typical lower current sleep patterns of wearables without any additional cost or complexity in hardware design.

\section{REFERENCES}

[1] C. Vallejos de Schatz, H. Medeiros, F. Schneider and P. Abatti, "Wireless medical sensor networks: design requirements and enabling Technologies", Telemedicine and e-Health, vol. 18, no. 5, pp. 394-399, 2012

[2] F. Simjee and P. Chou, "Efficient charging of supercapacitors for extended lifetime of wireless sensor nodes", IEEE Trans. Power Electron., vol. 23, no. 3, pp. 1526-1536, 2008.

[3] J. Cho, Y. Woo, S. Kim, and E. Seo, "A battery lifetime guarantee scheme for selective applications in smart mobile devices", IEEE Trans. Consum. Electron., vol. 60, no. 1, pp. 155-163, 2014.

[4] A. Etxeberria, I. Vechiu, H. Camblong and J. Vinassa, "Comparison of three topologies and controls of a hybrid energy storage system for microgrids", Energy Conversion and Management, vol. 54, no. 1, pp. 113-121, 2012.

[5] R. Chaari, O. Briat and J. Vinassa, "Capacitance recovery analysis and modelling of supercapacitors during cycling ageing tests", Energy Conversion and Management, vol. 82, pp. 37-45, 2014.

[6] P. Kreczanik, C. Martin, P. Venet, G. Clerc, G. Rojat and Y. Zitouni, "Constant power cycling for accelerated ageing of supercapacitors", in 13th European Conference on Power Electronics and Applications, Barcelona, Spain, 2009, pp. 1-10.

[7] N. Stryzhakova, "Testing Methodology Manual," 2012. [Online]. Available: http://www.energycaps.eu/wpcontent/uploads/2013/09/Testing-Methodologies-Manual.pdf. 